\title{
An online image analysis tool for science education
}

\author{
L. Raeside *, B. Busschots, S. Waddington, J.G. Keating \\ Education through Virtual Experience (EVE) Research Group, Department of Computer Science, National University of Ireland, \\ Maynooth, Maynooth, County Kildare, Ireland
}

Received 30 April 2007; received in revised form 13 September 2007; accepted 18 September 2007

\begin{abstract}
This paper describes an online image analysis tool developed as part of an iterative, user-centered development of an online Virtual Learning Environment (VLE) called the Education through Virtual Experience (EVE) Portal. The VLE provides a Web portal through which schoolchildren and their teachers create scientific proposals, retrieve images and other resources, and produce collaborative scientific papers summarizing their learning experiences. The VLE underwent substantive formative testing involving over 200 schoolchildren producing over 50 collaboratively written research papers. Detailed analysis of these research papers identified some shortfalls toward the goal of producing authentic scientific engagement. The absence of data collection and data analysis within these research papers was disappointing despite having scheduled time for this activity and having several professional imaging tools available. The post-evaluation analyses have enabled the development team to identify specific design flaws in the previous VLE and have shaped the design of the new custom-built tool. The success of the tool will be born out through content analysis of future collaboratively written student papers.
\end{abstract}

(C) 2007 Elsevier Ltd. All rights reserved.

Keywords: Cooperative/collaborative learning; Interactive learning environments; Secondary education; Applications in subject areas

\section{Introduction}

This paper describes an online image analysis tool developed as part of an iterative, user-centered development of an online VLE called the EVE Portal. The VLE provided a suite of software tools used by schoolchildren and their teachers to complete Astronomy-based scientific investigations within a social constructivist paradigm (Bruner, 1996; Driver, Asoko, Leach, Mortimer, \& Scott, 2004). The EVE Portal was developed to engage schoolchildren in inquiry-based learning activities that culminate in the production of written documents that summarize the experiences of the teams of schoolchildren. Inquiry-based learning using ICT has been emerging for decades; for example, Papert developed the LOGO environment to engage students in activities and to learn from their experiences through experimentation (Papert, 1993). Later learning environments, such as Computer-Supported Intentional Learning Environments (CSILE) utilize the networking

\footnotetext{
* Corresponding author. Tel.: +35318851168.

E-mail address: luke.raeside@itb.ie (L. Raeside).
} 
capabilities of computers so that students can carry out investigations as groups rather than individually (Scardamelia \& Bereiter, 1994). The Internet now provides an ideal environment for team-based inquiry activities where groups of students, not necessarily co-located can work together to achieve a goal. Many environments exist with inquiry-based investigation as the central goal, for example, Linn, Davis, and Bell (2004) have developed an inquiry-based science learning environment called Web-based Inquiry Science Environment (WISE); this environment contains a set of integrated tools to support and engage students in inquiry-based activities including collaborative analysis and reporting. The WISE environment has evolved to become completely Web-based and "does not require installation" this has been one of the main technical goals of our development since the EVE project began; provision of a completely Web-based solution simplifies deployment to the school environment and maximizes availability. Another example of an inquiry-based learning environment is the digital document discussion environment $\left(D^{3} E\right)$ developed at the Open University (Laurillard, 2003), this environment allows the teacher to post a resource and engage students in discussions relating to the resources. Laurillard states that learning environments like $\mathrm{D}^{3} \mathrm{E}$ can "enable students to act in some way like scientists - experimenting, analyzing, discussing, comparing, interpreting"; the EVE Portal shares the aim of engaging students to $d o$ science and engage in discourse relating to the subject under investigation. The EVE VLE has to-date focused only on Astronomy applications, however, it became apparent to us during testing that the VLE was not limited to astronomical applications and recently there has been a new emphasis within the development team to expand to scope of the VLE to other disciplines. The image analysis tool outlined in this paper provides students using the VLE with the ability to view images and carry out measurements on the images within the portal. This image analysis tool provides an essential adjunct to the collaborative inquiry-based activities carried out using the VLE by providing software support for the collection of raw image data.

Scientific investigations involve the formulation of hypotheses, the gathering of data to support or reject the hypotheses and finally the production of a written paper through which conclusions can be drawn. This process is rarely completed individually and more often involves collaboration between peers. Collaboration with peers is central to authentic science learning. Authentic writing assignments, using a constructivist model (incorporating writing scaffolds), should be delivered concurrently with student reading, investigation and research and would require the use of portfolio-based techniques as outlined by Haines (2004) who suggests that ICT is an essential tool in assisting peer- and self-assessment in authentic social constructive learning environments, be they virtual or real. The imaging tool supports collaboration by allowing students to gather data individually and later include that data into the final research paper. The data gathered provide evidence for the support or rejection of the teams' original hypotheses.

The examination and investigation of visual phenomena is not limited to Astronomy, however, astronomical images can be truly spectacular and have the ability to spark the imagination of participants and thus have provided a great medium to explore the role that images can play in the engagement of schoolchildren in scientific discovery. The image data collected using the tool are centered on the elementary measurements of length and angle and therefore can be applied readily to Science curricula. Imaging in Astronomy relies heavily on a data format standard known as Flexible Image Transport System (FITS), which has been used by astronomers since the 1970s (Greisen \& Calabretta, 2002; Grosbol, 2005; Hanisch et al., 2001). As well as optionally storing an image within the visual spectrum this format contains header information useful for astronomical analysis, including: information about the telescope where the image was taken, time-based data, data associated with the field of view and information associated with the coordinates of the region in the sky where the image was taken. This rich source of data can be extracted from the image using the imaging tool outlined herein. Students can perform a variety of scientific inquirybased activities using this extracted data within the VLE and can generate additional data using this custom-built analysis tool. The measurement data generated by the tool are similar to that found in many astronomical image analysis tools, for instance the LTImage software produced by the Schools' Observatory (schoolobservatory.org.uk, 2007). The EVE imaging tool, however, is not intended as a standalone software component for data collection and analysis it is completely integrated within the inquirybased process supported by the entire suite of tools in the VLE, the imaging tool itself will only be used within the context of a project assignment, therefore, the emphasis on report writing and inquiry remains central. 


\section{The VLE}

The VLE was constructed through a series of increments and incorporated the feedback supplied by 10 local schoolteachers and their students. In the formative stages the teachers and their students provided requirements and helped to evolve the VLE through use of the environment and through direct input into the project. Section 3 contains a more detailed description of the evaluations. The VLE, in its present form, is composed of several software components and operates completely within the browser environment. The VLE is composed of the following software components:

1. The Collaborative Writing Environment (CWE): A collaborative writing environment for students and their teachers. This provides an environment for the allocation of virtual teams, project design, document design and the collaborative document writing (Busschots, Raeside, Waddington, \& Keating, 2006).

2. The Scrapbook: A collaborative resource sharing and storage tool. Students can persistently store data, text, images, hyperlinks and other resources pertaining to the project (on a server). Students can also share these resources with other members of their team and can import resources directly into the team research paper and other integrated components.

3. The Commenting Context: This component allows students and teachers to provide text-based feedback to each other, these feedbacks are very important to the success of the collaboration within teams and between the teams and their teachers.

4. The Support Tools: The VLE provides fully integrated tools to support the data collection and data analysis phase of a project. This includes the imaging tool.

Together these software components link the team allocation, research, writing and analysis phases into a software supported collaborative process. The imaging tool described herein is part of this amalgamation of software components designed to support collaborative research projects.

\section{VLE evaluations}

This section provides a summary of the evaluations that took place on the VLE. These evaluations are described in detail in another publication currently in press (Busschots, Raeside, Keating, \& Hoban, in press); however, we provide this summary of the sessions to outline the method of requirements gathering employed and their influence of the imaging tool's design. These formative evaluations were used to incrementally development the CWE, the Scrapbook component and the imaging component described herein. The first phase of the VLE development involved the creation of a prototype VLE followed by formative evaluations ultimately involving more than 200 schoolchildren and their teachers over three years. The evaluations were carried out to refine the prototypical VLE design and to determine whether the VLE could support the engagement of children in an inquiry-based process. This study also attempted to highlight usability and practical issues to be resolved prior to deployment in a school environment.

The prototype VLE consisted of an aggregation of separate software components, which together supported most of the student activities. The majority of the activities were supported by third-party software packages; however, the paper writing activity was supported by the Paper Writing Component (an early version of the CWE), which was written by the EVE development team. The remaining activities were supported without the use of software; for example, the resource sharing activities were not supported within the software, resource sharing was achieved by supplying the participants with pens, paper and $3.25^{\prime \prime}$ diskettes.

The evaluations included the gathering and analysis of observational data, detailed content analysis of Project Reports produced by the students and a qualitative survey-based assessment of the reports by independent teachers. The observational results were most useful for improvements to the software, again in a similar way to the development of WISE, Christopher M. Haodley describes the continuous improvement of the design and processes and states that "Good design is iterative" and that improvements are found as the software is "tested, observed" and then "refined" (Linn et al., 2004, p. 146). The EVE prototype VLE was initially evaluated during three Science Summer Camps held at NUI Maynooth. One camp was held each summer over these three years and the EVE team delivered a different session using the prototype VLE at 
each. The data from which conclusions were drawn included observation reports, participant comments, and 52 Project Reports produced by small groups using the Paper Writing Component. Fig. 1 shows an example of the type of output produced by the student teams during the evaluations. This research paper was generated in July 2004 at NUI Maynooth and involved a team of five students aged 15-17 years. The students used a telescope located in Mount Wilson; Los Angeles, California to capture images of a galaxy called M51 and used the Internet to retrieve an image of the Hubble telescope.

In all, three iterations of the prototype VLE were evaluated. Although some of the software components were changed from year to year, the objectives of the VLE remained constant, i.e. to engage children in an inquiry-based process and produce Project Reports summarizing their experiences. Each session had clear learning objectives that were presented to the participants before they used the VLE. The EVE team planned all of the lab session activities prior to delivery (Fig. 2 shows a sample lesson plan). Different themes were chosen for each of the Astronomy sessions, the themes chosen were: The Electromagnetic Spectrum (2002), The Life of a Star (2003) and Galaxies (2004). A summary table giving the details of the pupil profile and the themes are shown in Table 1. Within each session there were a sufficient number of workstations so that the children each had a computer. The working environment was consistent throughout the three years and facilitating staff, a Team Leader (EVE project personnel) and several demonstrators (Department of Computer Science graduate students) were present during each session. The students previously knew none of the staff and all staff members were dressed informally and introduced themselves with their first names. A similar lesson plan to that shown in Fig. 2 was developed for each of the sessions. All sessions started with an introduction of the module topic, the VLE was introduced, and the team leader explained some very basic

M51

Niamh,tina, alex Caitriona,aoife

\section{Abstract}

Our group is going to tell you about the galaxy M51. We hope you enjoy it.

Key words:

HICSS. VTIE, NUI Maynooth

1 Introduction

Our story begins with the discoverer of this amazing new world.Charles Messier was born in France. He discovered the Galaxy on October 13th,1773. He was fasinated by this strage artifact. Then, in 1845 , an Irishman, Lord Rosse discovered that it was a spiral structure. He built two telescopes, the first a 36 inch, the next a spectacular 72 inch. This baffled the world. The 72 inch telescope took two long years to build. It was named 'The Leviathan of Parsonstown'.Hubble law was all galaxies were moving away from each other-the further away the faster.

2 Olsservation

Our galaxy is $11 \times 7$. Its brightness is 8.4 [mag]. It distance away is an estimated 37 million light years away.It is a spiral stucture which was discovered by Lord Rosse.M51 was first discovered in october $1773 . \mathrm{M} 51$ 's discoverer was born in France.

3 Conclusion

Today, we did lots of interesting research on the galaxy MI51. We had heaps of fun and found out lots of things that we never knew before. Well,that is the

end of our report. We hope it has filled you with a newinsipration for science on study of the galaxy. Well thats it for now Yours, Niamh, Caitriona, Martina, Alex and Aoife.

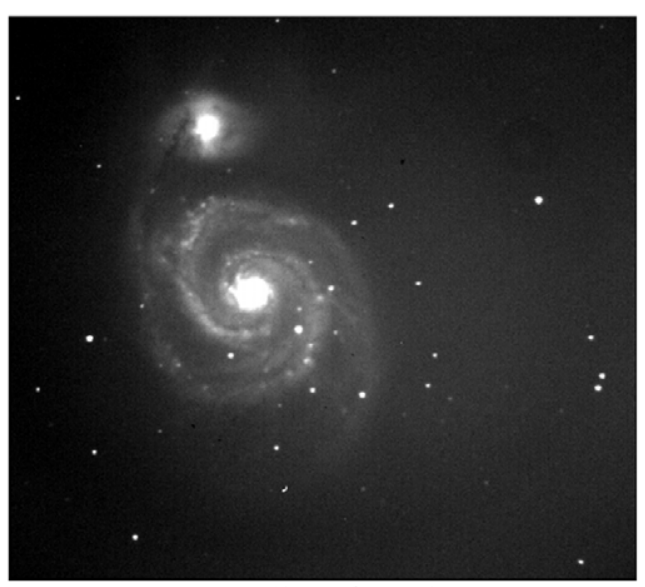

Fig. 1. M51 from Mount Wilson

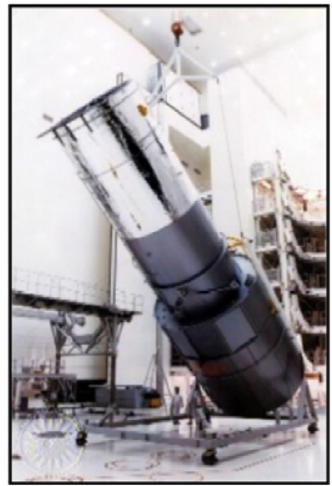

Fig. 2. The Hubble Space Telescope

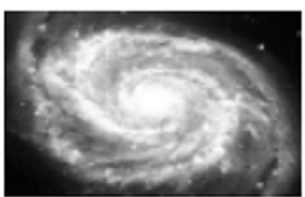

Fig. 3. M51

Fig. 1. Sample student research paper. 


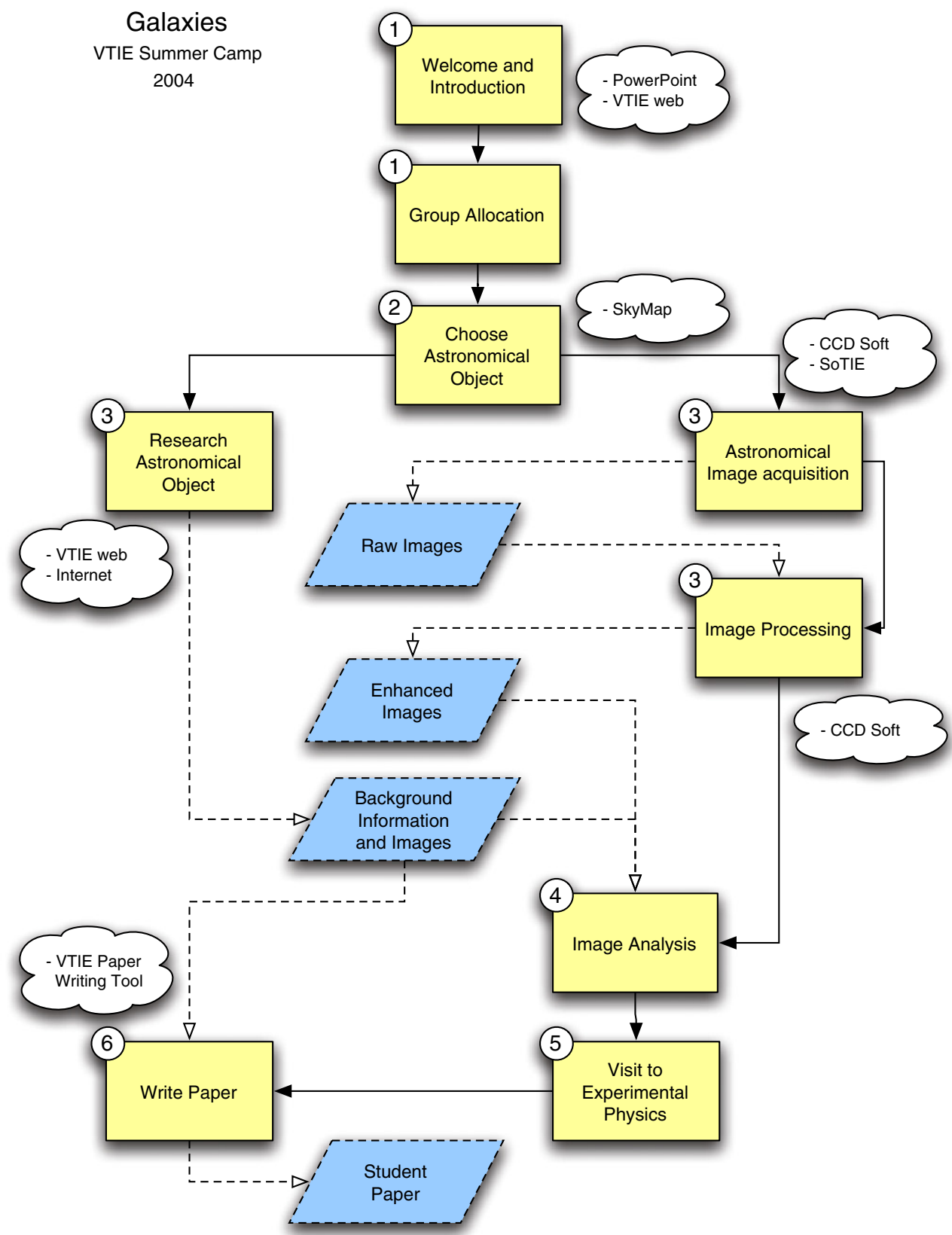

Timeline

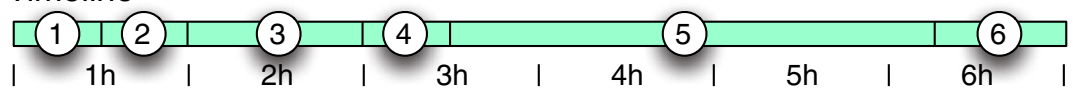

Fig. 2. Lesson plan for Galaxies sessions.

Table 1

Summary table of formative evaluations

\begin{tabular}{lllrl}
\hline Year & Theme & Telescope & Profile & Duration $(\mathrm{h})$ \\
\hline 2002 & Spectrum & $24^{\prime \prime}$ Mt. Wilson & $130(13-17)$ & 3 \\
2003 & Life of Star & $14^{\prime \prime}$ Mt. Wilson & $30(16-17)$ & 6 \\
2004 & Galaxies & $14^{\prime \prime}$ SoTIE Chile & $20(16-17)$ & 6 \\
\hline
\end{tabular}


Table 2

Summary table of assistance required during evaluations

\begin{tabular}{llll}
\hline & Spectrum (2002) & Life of Star (2003) & Galaxies (2004) \\
\hline Choose Astronomical object & - & - & 3 \\
Research Astronomical object & 3 & 3 & 1 \\
Astronomical image acquisition & 5 & 4 & 5 \\
Image processing & 5 & 5 & 5 \\
Image analysis & 5 & 5 & 1 \\
Write paper & 2 & 1 & 1 \\
\hline
\end{tabular}

Astronomy concepts. After the introduction the participants were broken into groups, each group then selected an astronomical object to study. All modules included a research phase during which the participants assembled background information on their chosen object. The children also controlled a telescope and collected and processed telescope images during this phase. Finally, each group wrote a Project Report using the Paper Writing Component. Demonstrators were requested to make observations while facilitating the sessions and discrete notes were taken for later evaluation. Post-trial meetings took place following the laboratory sessions to discuss observations made during the sessions. Each demonstrator was charged with attributing a value judgment on the level of assistance requested for each phase of the session plan. A recorded value of ' 1 ' indicated little or no help was requested during that phase, and a value of ' 5 ' indicated that continuous or near-continuous assistance was requested. A summary of the average values attributed can be found in Table 2, this table provided the development team with a starting point to assess where improvements could be made in the next version of the software.

\section{Requirements analysis for imaging component}

Substantial information was gathered through the course of the evaluations. Observational results were analyzed and discussed during meetings held following each session. The demonstrators facilitating in the laboratory were specifically instructed to observe the students' use of the software during the laboratory sessions. Results were also obtained through analysis of the output constant from all the laboratory sessions, i.e. the Project Reports produced by the participants. Finally, 14 teachers participated in a survey-based assessment of the quality of the Project Reports produced by the EVE participants. The observational data were of particular interest to the development team as this helped to identify shortfalls with the current software and produce new requirements to be included in later iterations, these observational data were the source of requirements elicitation for the imaging component. The evaluation results indicated to the development team that the Paper Writing Component was very successful during the sessions and should be used as the exemplar for further development.

As stated above the data in Table 2 were derived from the post-session meetings and discussions with the demonstrators. These data clearly showed that the demonstrators reported that the image processing phase of the sessions required near-continuous assistance. This phase, therefore, was perceived to be problematic by the development team. Possible causes for this near-continuous assistance were discussed during post-evaluation meetings, and it was concluded, based on observations that the students were confused by the many image modification options available when, in fact, there were only a few functions that were relevant to the objectives of the sessions. The requirement to reduce the level of processing options available in the imaging tool was therefore elicited and a design decision was made to make the necessary processing options prominent. According to the data the image analysis phase also required near-continuous assistance, however, the exception to this was the Galaxies sessions. This was mainly due to the fact that the image analysis was a purely visual examination of the image in the Galaxies session, i.e., we had reduced the complexity of the image analysis phase having experienced difficulties with the previous attempts. The development team made another design decision for the new imaging component, namely, to make the measurement functions more visible and easy to accomplish for the novice user.

As part of the evaluations a thorough content analysis of the student research reports was undertaken, the results of this analysis also had implications for the development of the imaging tool. Each group of children 
that participated in a session completed a Project Report describing their work. When analyzing these reports our aim was twofold. Firstly, to extract any information in the reports about the software and secondly, to investigate the degree to which students completed the tasks as laid out in the lesson plans. Each Project Report was scored under five different criteria; one of these criteria was directly relevant to the imaging component. Specifically, each report was examined for the level of image analysis information it contained. Each Project Report was scored on a 5-point Likert scale from 'very poor' to 'very good'. Reports that contained no evidence of image analysis were considered 'very poor' and reports that showed evidence that the children could extract information from the images and form conclusions based on this information were considered 'very good'. Few reports scored highly; reports predominantly scored 'average'. This category also had the lowest average score of all the categories scored on 5-point Likert scales. Table 2 indicated that, in the two years where the image analysis phase was considered key, the children requested a lot of assistance during this phase. This analysis indicated to us that the imaging phase would require better support in later versions of the VLE.

Apart from any of the analysis carried out as described above, we, as educators were not of the opinion that the students had met our expectations for image data collection in any of the sessions. None of the student reports contained measurement data relating to the images acquired. There were several clearly defined measurement activities planned by the team prior to the sessions, for example, we had originally intended for the imaging phase of the Galaxies session to contain the measurement of the angular width of a Galaxy. However, the difficulties in achieving even the simplest processing tasks meant that these activities were not even attempted. The measurements themselves are not complex, but the difficulties with the software prevented participants from beginning these tasks. It is possible that the expectations for the image data collection and image data analysis were not reasonable, nevertheless, these evaluations clearly demonstrated to us that the VLE was not providing a suitable platform from which to begin to explore the scope of image

Table 3

Summary of imaging requirements analysis

\begin{tabular}{|c|c|c|c|}
\hline Observed difficulty & Example & Requirement elicited & Requirement response \\
\hline $\begin{array}{l}\text { Imaging tools made assumptions } \\
\text { about knowledge of user of the } \\
\text { user, e.g., assumes student knows } \\
\text { what 'reasonable' input values } \\
\text { for thresholds }\end{array}$ & $\begin{array}{l}\text { Manual entry of threshold values: } \\
\text { students constantly requested } \\
\text { assistance when entering threshold } \\
\text { values, this is required to make } \\
\text { features in an image visible }\end{array}$ & $\begin{array}{l}\text { Provide simple } \\
\text { options, minimize } \\
\text { manual entry, build } \\
\text { for child user }\end{array}$ & $\begin{array}{l}\text { The imaging tool provides slider for } \\
\text { threshold value input, this will allow } \\
\text { the student to freely experiment with } \\
\text { possible 'reasonable' values }\end{array}$ \\
\hline $\begin{array}{l}\text { Students found it difficult to swap } \\
\text { from the browser to standalone } \\
\text { software }\end{array}$ & $\begin{array}{l}\text { Students had multiple windows } \\
\text { open, all with different interaction } \\
\text { styles }\end{array}$ & $\begin{array}{l}\text { Produce tools that } \\
\text { operates within the } \\
\text { existing portal } \\
\text { (improve } \\
\text { cohesiveness) }\end{array}$ & $\begin{array}{l}\text { Imaging tool is fully integrated } \\
\text { within portal in terms of use in the } \\
\text { browser, linking and look-and-feel }\end{array}$ \\
\hline $\begin{array}{l}\text { Students found it hard to load } \\
\text { images and it was difficult to } \\
\text { share/move images }\end{array}$ & $\begin{array}{l}\text { Students were forced to walk } \\
\text { around the lab with disks and pen } \\
\text { drives }\end{array}$ & $\begin{array}{l}\text { Fully integrate } \\
\text { imaging with } \\
\text { Scrapbook and CWE } \\
\text { allowing easy } \\
\text { sharing/loading }\end{array}$ & $\begin{array}{l}\text { Current version of image tool shares } \\
\text { images directory with Scrapbook } \\
\text { and Scrapbook provides direct } \\
\text { image sharing }\end{array}$ \\
\hline $\begin{array}{l}\text { Students only used the imaging } \\
\text { tools to make objects look nicer }\end{array}$ & $\begin{array}{l}\text { Students requested frequent help } \\
\text { when searching menu options }\end{array}$ & $\begin{array}{l}\text { Simplify the imaging } \\
\text { options and make the } \\
\text { measurement options } \\
\text { prominent }\end{array}$ & $\begin{array}{l}\text { The imaging tool has only a few } \\
\text { basic necessary options available } \\
\text { this in turn makes the measurement } \\
\text { options more prominent }\end{array}$ \\
\hline $\begin{array}{l}\text { Every team included images in their } \\
\text { paper but not possible direct } \\
\text { from imaging tools }\end{array}$ & $\begin{array}{l}\text { Each research paper produced } \\
\text { contained at least one image } \\
\text { despite difficulties }\end{array}$ & $\begin{array}{l}\text { Provide simple } \\
\text { mechanism for } \\
\text { inclusion of images } \\
\text { into the student } \\
\text { research paper }\end{array}$ & $\begin{array}{l}\text { The imaging tool shares image } \\
\text { directory with the Scrapbook which } \\
\text { provides one-click addition to final } \\
\text { research paper }\end{array}$ \\
\hline $\begin{array}{l}\text { Virtual collaboration not achievable } \\
\text { with standalone tools }\end{array}$ & $\begin{array}{l}\text { The imaging tools hampered } \\
\text { virtual collaboration with reliance } \\
\text { on manual swapping between } \\
\text { applications }\end{array}$ & $\begin{array}{l}\text { Make virtual } \\
\text { collaboration possible } \\
\text { with fully integrated } \\
\text { imaging tool }\end{array}$ & $\begin{array}{l}\text { The imaging tool is integrated and } \\
\text { has links to the system from the } \\
\text { browser, and has direct shared } \\
\text { access to VLE database tables }\end{array}$ \\
\hline
\end{tabular}


data collection and analysis possible. There was no prospect of successfully mapping the angular movement of astronomical objects given that the students were finding it so difficult to format the images for display. We hypothesize that the new imaging component detailed in this report will provide a more appropriate software platform for exploration of the scope of image data collection and analysis using the VLE and will better equip us to assess the level of expectation we should have in future sessions.

The Paper Writing Component used in the evaluations has evolved into a collaborative writing environment, which addresses many of the deficits identified during the evaluations. During the evaluations of the VLE students were assigned to teams manually and this has now been captured virtually using the CWE. Additionally, the facilitator of the groups of students may now use the Project Management interface (part of the CWE) to assign students to particular sections of the team report and each student is responsible for the completion of that section. The students then complete their investigations of astronomical objects within their team. The development team has already undertaken focused evaluations of the CWE specifically identifying how the changes have affected the output. These tests have followed the same lesson plans as the initial evaluations. The improvements to the Paper Writing Component have demonstrated to us the effectiveness of the evaluation approach employed; similarly the imaging tool will undergo further focused testing to ensure that we have come closer to our goals. Table 3 summarizes the main observations relating to the imaging activities, the requirements elicited from these observations and the design responses to those observations. In addition to the requirements elicited from the laboratory observations some general requirements

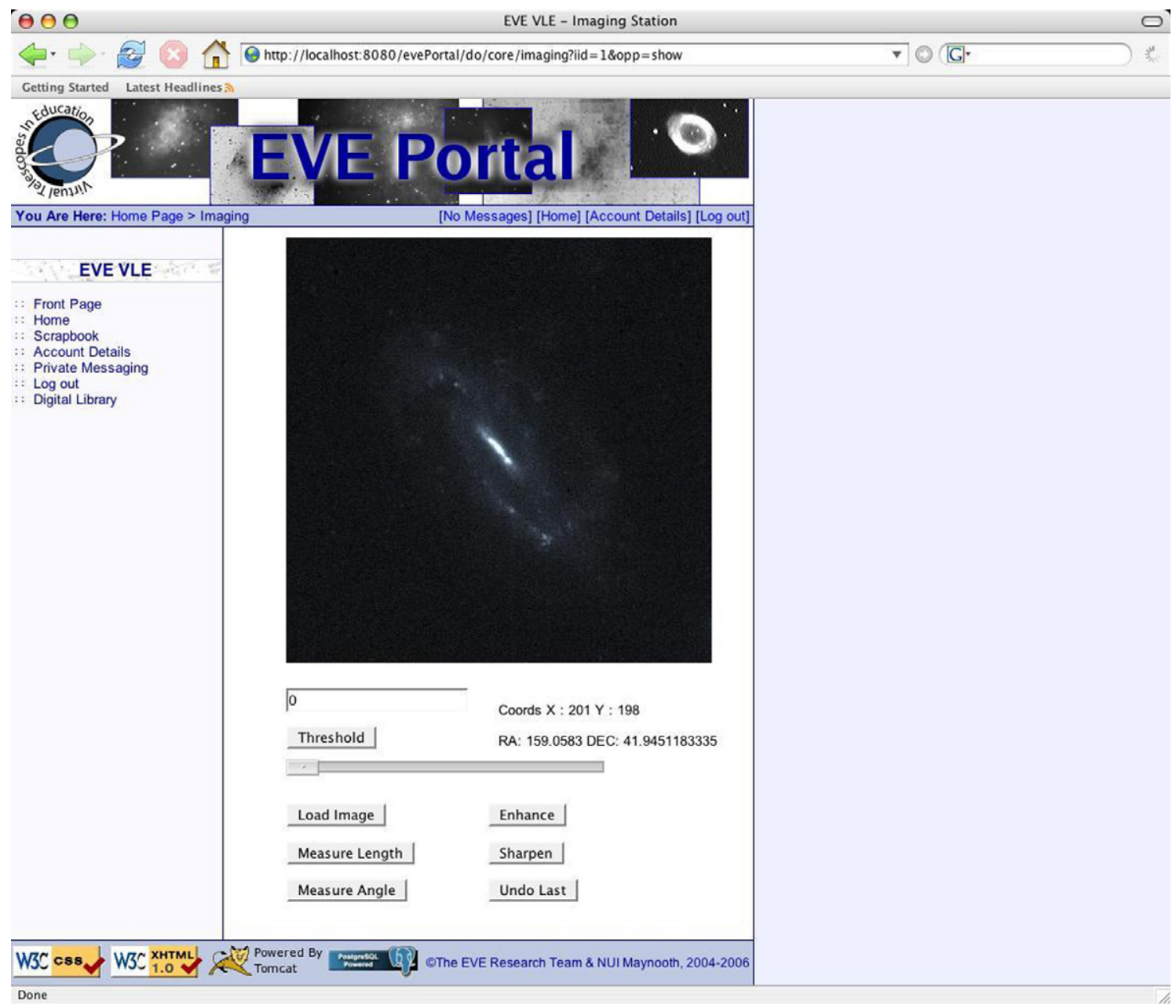

Fig. 3. Fits data retrieval function. 
stated by the participating teachers also influenced the development of the imaging tool, for example, the teachers stated that the entire VLE should be free, require no installation, be easy to use by students/teachers and should involve teamwork and collaboration. The third-party imaging tools used in the evaluations inhibited the development team's ability to satisfy these general VLE requirements, particularly the installation and collaboration requirements. Finally, delivering a fully integrated imaging tool would simplify the entire process of making the images persistent thereby making it possible to carry out data collection over extended and disjoint periods of time.

\section{The imaging tool}

The goal of the imaging tool is to provide an integrated means for image related data collection and thus enhance the authenticity of the scientific inquiry within the VLE. The image measurements are based on length and angle measurements, which are frequently used in Astronomy. The imaging tool provides the following functionality:

\subsection{Viewing of FITS images in the browser window}

The FITS image standard is not compatible with the browser and cannot be rendered in its native format. The imaging tool carries out image conversion and displays a browser compatible representation of the FITS

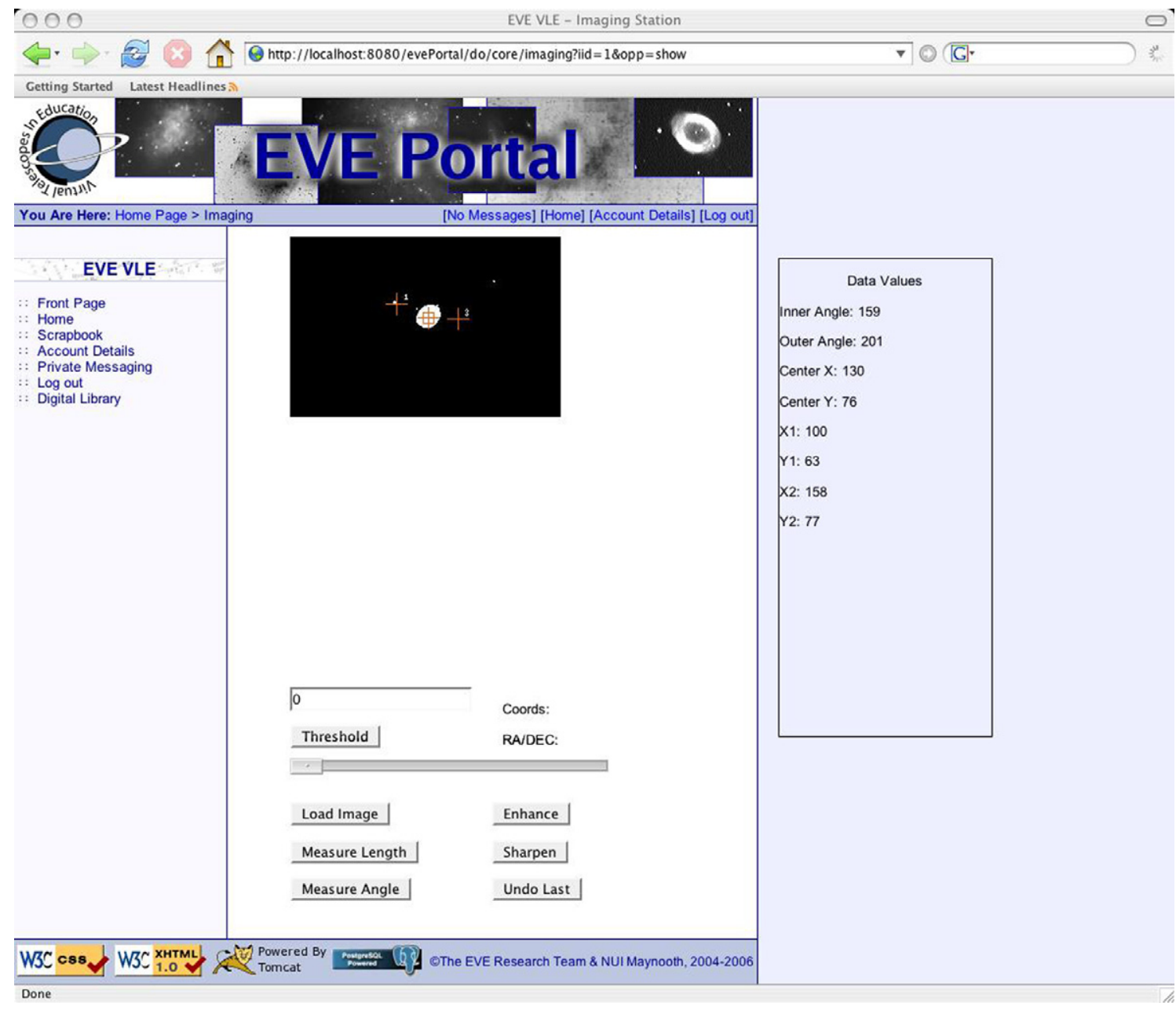

Fig. 4. Position angle of Titan to Saturn. 
image in the browser window. The original FITS image is stored at the server where the header information is read and returned to the browser in XML format when requested by the user.

\subsection{Basic image processing}

FITS images are not always in a state that shows pertinent details to the observer. The imaging tool provides some very basic image processing functionality to the user, including enhancement, sharpening and thresholding. A slider bar controls the thresholding so that manual entry of arbitrary values by the user is not expected. The simplicity of the options available reduces the level of complexity for the schoolchildren and makes the measurement options more prominent.

\subsection{Mapping of image coordinates to equatorial coordinates}

Equatorial coordinates locate astronomical objects in the sky using two coordinates, namely, the Right Ascension (RA - clockwise angle on the horizon) and Declination (DEC - vertical angle from the horizon). The imaging tool retains a copy of the FITS header information at the server; this includes the coordinate header information where available. The student can retrieve the equatorial coordinates for a corresponding $x$ and $y$ pixel location on the image simply by double-clicking on the desired image location. Retrieving these

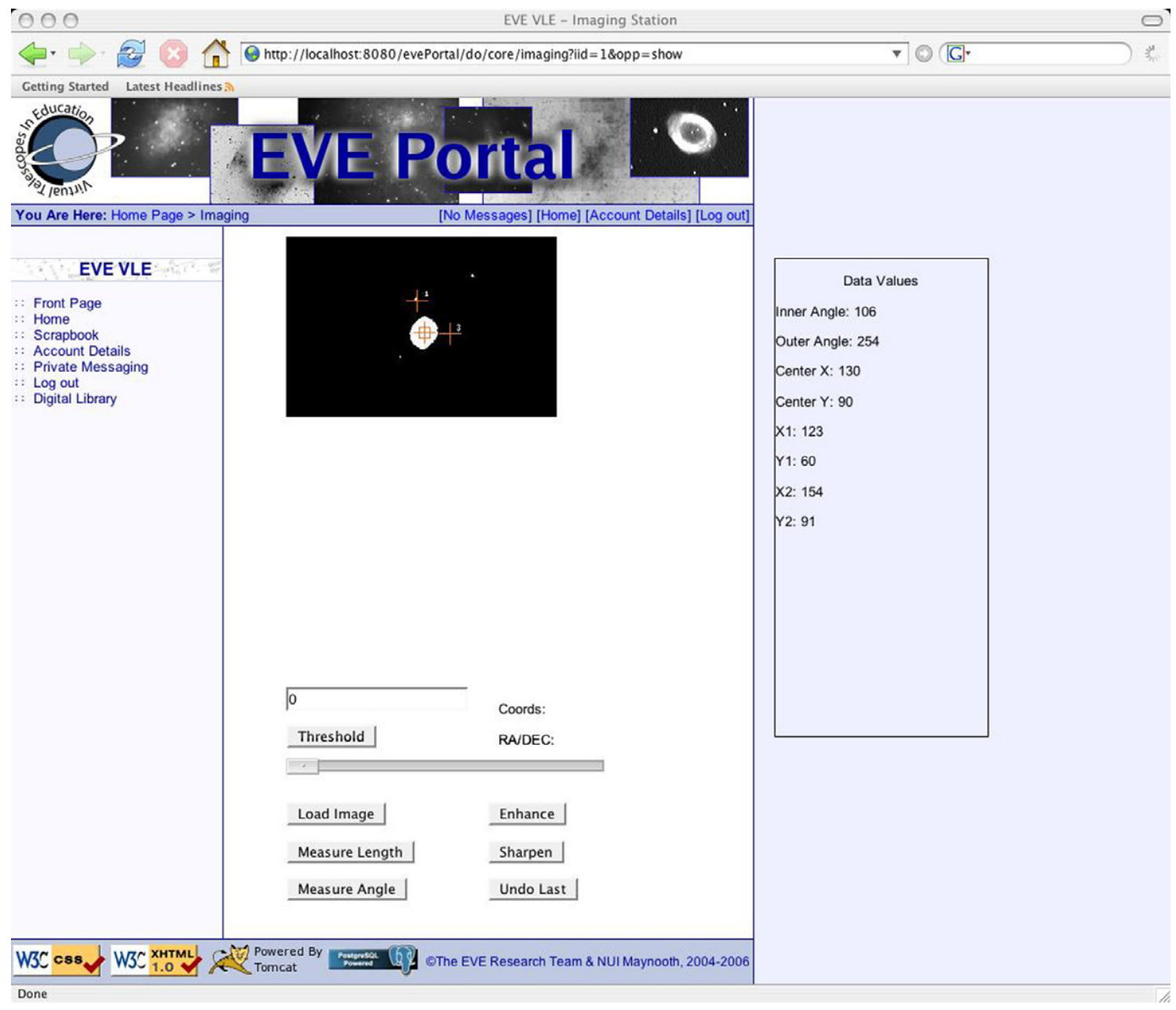

Fig. 5. Position angle change of Titan to Saturn. 
coordinates enables the students to carry out computations, for example, the angular size of a galaxy can be measured by recording the coordinates of the extremities of the object and calculating the number of degrees the object spans. Fig. 3 shows an example of these data retrieval function in operation, the coordinates for the point were returned as RA of 159.0583 and DEC of 41.9451183335.

\subsection{Pixel length measurement}

The imaging tool supplies a simple single-click mechanism for the measuring of the length in pixels between two points in an image. The schoolchildren select the measure length option and then place a cross hair at the starting point and another cross hair at the finishing point. The pixel length is then displayed in a data window. These length measurements can be used to compute angular size and angular distance measurements.

\subsection{Angular measurement}

Finally the imaging tool provides a single-click angular position measurement function. The student can use this to measure the position angle of one astronomical object relative to another. Figs. 4, 5 and 6 show the sequential change of position angle of Titan (Saturn's largest moon) relative to the planet. The angular measurements are generated by placing three cross hairs on to the region of interest in the image. The initial angular measure in this example was recorded as $159^{\circ}$ relative to the planet; the subsequent measurements show how the position angle of the moon relative to the planet changed over time. This example illustrates how the imaging tool can be used to track the change in Titan's angular position relative to Saturn over time; however, the imaging tool can be used to measure the angular position of any object in an image relative to another. This data could be used to simply show that a moon in fact orbits its planet, or this data could be used to prove the hypothesis that it takes 15.94 days approximately for Titan to complete one full revolution of Saturn. Tracking the change in position angle of objects from within the VLE will provide a variety of experimental case studies from the very simple to the potentially complex. The complexity of the experiments is dependent only on the availability of images and the imagination of the teacher and the students.

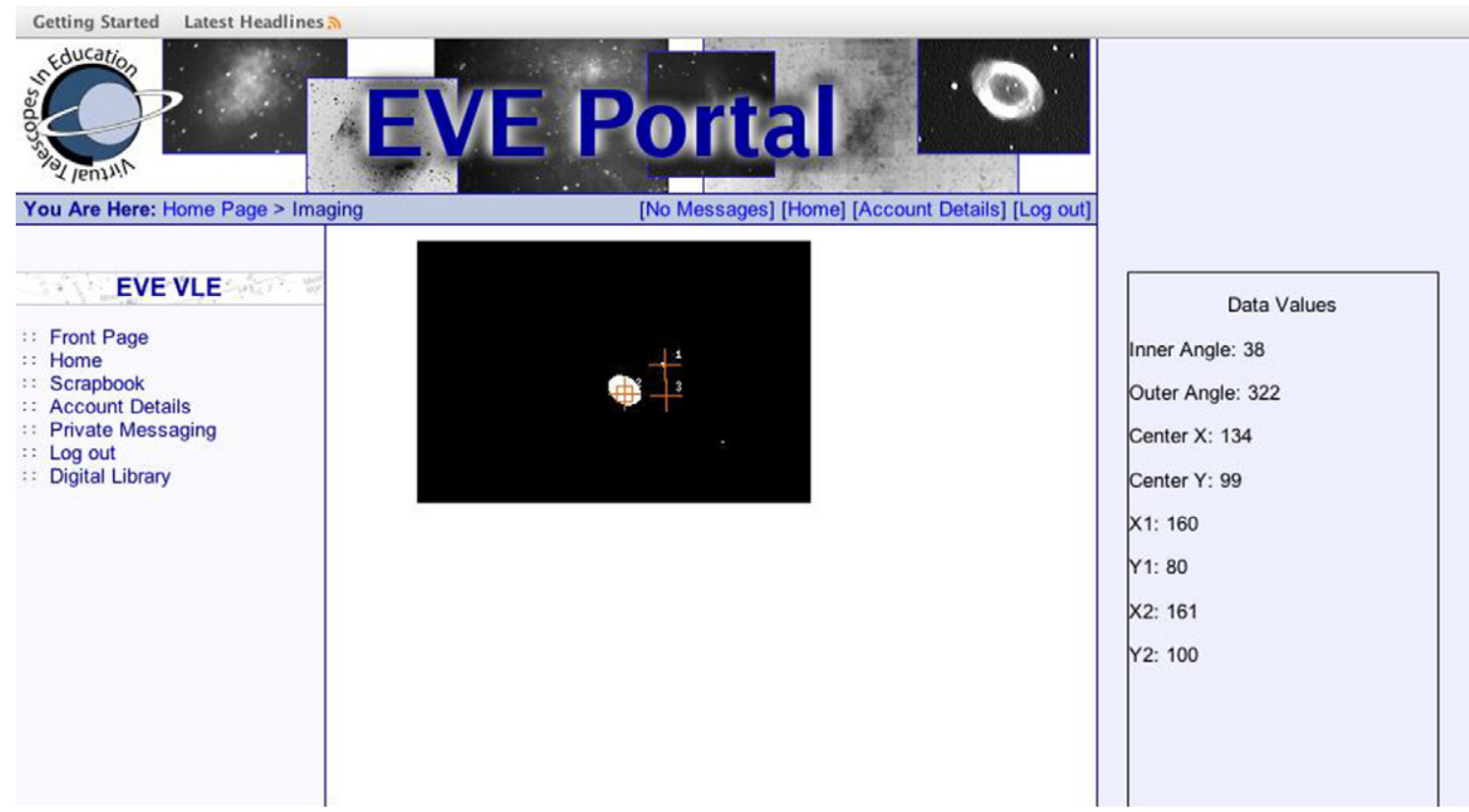

Fig. 6. Second position angle change of Titan to Saturn. 


\section{Integration and testing}

End-user testing of the imaging tool will be carried out in conjunction with the other VLE components and special attention will be given to the success or failure of the imaging phase in the post-trial analyses. The students will follow a similar lesson plan, as was the case in the previous evaluations. As with previous evaluations the output from the students will take the form of collaboratively written research papers and subsequent content analysis of these reports will allow us to assess if the new tool has helped to narrow the gap between our educational objectives and the student output. The imaging tool's application is not limited for use with astronomical images and future testing of the VLE will expand into data collection within different disciplines. Currently we are planning to expand the use of the imaging tool for exploration of aerial images in a Geography context.

\section{Conclusions}

The imaging tool described in this paper has been developed following extensive user-centered testing and with direct feedback from teachers and students. The next phase of testing of the VLE will produce a new set of student research papers. It is hypothesized that the new imaging tool will aid in the completion of image related data collection activities and that the participating students will analyze these raw data. The level of raw data collected and level of analysis achieved will be examined through further detailed content analyses of the student output and comparisons will be drawn with the previous evaluations' content analyses.

\section{References}

Bruner, J. S. (1996). The culture of education. Harvard University Press.

Busschots, B., Raeside, L., Waddington, S., \& Keating, J.G. (2006). The VTIE collaborative writing environment. In Proceedings of the 2nd international WEBIST conference on web information systems and technologies, Vol. 2 (pp. 221-228).

Busschots, B., Raeside, L., Keating, J.G., \& Hoban, S. (in press). Formative evaluations of a virtual learning environment for astronomy education. Computers and Education.

Driver, R., Asoko, H., Leach, J., Mortimer, E., \& Scott, P. (2004). Constructing scientific knowledge in the classroom. In Scanlon, E., Murphy, P., Thomas, J., Whitelegg, E., (Eds.), Reconsidering Science Learning (4th ed., pp. 58-73). London: Routledge.

Greisen, E. W., \& Calabretta, M. R. (2002). Representations of world coordinates in fits. Journal of Astronomy and Astrophysics, 395 , 1061-1075.

Grosbol, P. (2005). The JFITS application programming interface. http://www.hq.eso.org/ pgrosbol Accessed April 2007.

Haines, C. (2004). Assessing students written work. Abington, UK: RoutledgeFalmer.

Hanisch, R. J., Farris, A., Greisen, E. W., Pence, W. D., Schlesinger, B. M., Teuben, P. J., Thompson, R., \& Warnock, A. I. (2001). Definition of the flexible image transport system (fits). Journal of Astronomy and Astrophysics, 376, 359-380.

Laurillard, D. (2003). Mediating science learning through information and communications technology. In R. Holliman \& E. Scanlon (Eds.), Rethinking the teaching of science (pp. 44-45). London: RoutledgeFalmer.

Linn, M. C., Davis, E. A., \& Bell, P. (2004). Internet environments for science education. Lawrence Erlbaum.

Papert, S. (1993). Mindstorms: Children, computers and powerful ideas (4th ed.). Perseus Publishing.

Scardamelia, M., \& Bereiter, C. (1994). Computer support for knowledge building communities. The Journal of the Learning Sciences, 3(3), 265-283.

schoolobservatory.org.uk (2007). The National Schools' Observatory LTImage tool for image processing and image analysis. http:// www.schoolobservatory.org.uk. Accessed 02.08.07. 